\title{
MODELOS DE OCUPACIÓN Y ZONIFICACIONES TERRITORIALES EN NORTE DE SANTANDER, COLOMBIA - (REGIÓN DEL CATATUMBO).
}

\author{
Guillermo Hernando Quintana Machado ${ }^{1}$ \\ Grupo de Estudios Urbano Regionales del Magdalena Medio. \\ Instituto Universitario de la Paz UNIPAZ.
}

Remisión artículo: 17-07-2007

Palabras Clave: Ordenamiento Territorial, Modelos de Ocupación Territorial, Zonas de Reserva Forestal, Parques Nacionales Naturales, Territorios Étnicos.

Resumen: El presente artículo se elabora en base en el trabajo denominado "Modelos de Ocupación y Zonificaciones Territoriales en Norte de Santander, Colombia - Región del Catatumbo" presentado en el marco del Encuentro Nacional 10 años de la Ley de Ordenamiento Territorial: Una lectura desde las regiones de Colombia. Se desarrollan en éste los siguientes temas; inicialmente se realiza una caracterización del departamento Norte de Santander y del estado de los ordenamientos territoriales de sus municipios; posteriormente se define de manera general la región del Catatumbo en sus aspectos geográfico territoriales y sociopolíticos; a continuación se abordan las zonificaciones y modelos territoriales presentes en la región del Catatumbo, detallando cada una de ellas como son; la Zona de Reserva Forestal de la serranía de los Motilones, el Parque Nacional Natural Catatumbo - Barí, los Resguardos Indígenas Motilón - Barí y Catalaura y los Modelos de Ocupación Territorial al nivel municipal; finalmente se realiza una mirada actual al territorio del Catatumbo Nortesantandereano, examinando la institucionalidad en la región y planteando algunos retos en los distintos niveles e instancias territoriales.

\section{Situación general de los ordenamientos territoriales municipales en Norte de Santander.}

\subsection{Contexto departamental}

Norte de Santander, está ubicado en la región nororiental colombiana, limita con los departamentos de Cesar, Santander, Boyacá y con la República Bolivariana de Venezuela, (ver figura 1.)

El departamento tiene una extensión aproximada de 2.199.467 ha y una población proyectada a 2008, según el DANE de 1.275.781 habitantes de los cuales el 77,08 \% es urbano (983.408 habitantes) y el 22,92 \% (292.373 habitantes) es rural.

\footnotetext{
${ }^{1}$ Persona de contacto: Guillermo Hernando Quintana Machado, correo electrónico: guillermo.quintana@unipaz.edu.co, guillequintana@yahoo.com
} 
Norte de Santander por su carácter fronterizo presenta una gran dinámica funcional, por el corredor vial Bucaramanga - Pamplona - Cúcuta - Venezuela, se moviliza la mayoría del intercambio comercial con el vecino país. Sus principales ciudades son San José de Cúcuta, Pamplona y Ocaña, en dichos centros urbanos se concentra la mayoría de la población departamental.

Figura 1. Localización general del departamento Norte de Santander.

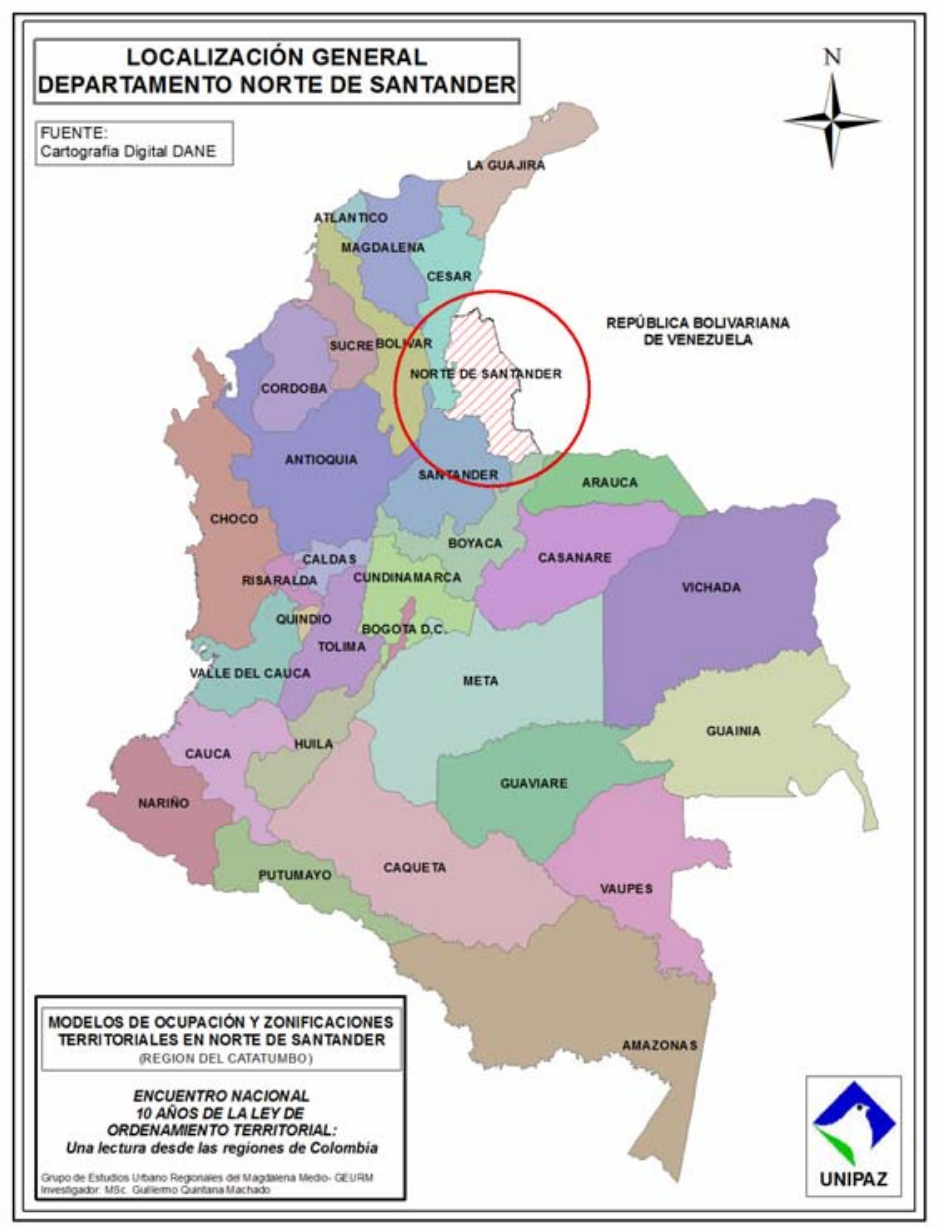

Fuente: Elaboración propia, (con base en cartografía DANE).

Norte de Santander cuenta con 40 municipios, los cuales están agrupados en 6 subregiones, tal como se muestra en la tabla 1, y se observa en la figura 2. El departamento tiene un área metropolitana conformada por cinco municipios; San José de Cúcuta, Villa del Rosario, Los Patios, El Zulia y San Cayetano.

La división político administrativa del departamento Norte de Santander, se puede observar en la figura 3. 
Tabla 1. Subdivisión en subregiones del departamento Norte de Santander.

\begin{tabular}{cccccc}
\hline Subregión & Municipio & Área (ha) & Subregión & Municipio & Área (ha) \\
CENTRO & ARBOLEDAS & 45545 & ORIENTAL & CÚCUTA & 114403 \\
& CUCUTILLA & 36882 & & EL ZULIA & 52137 \\
& GRAMALOTE & 14515 & & LOS PATIOS & 12942 \\
& LOURDES & 9634 & & PUERTO SANTANDER & 4509 \\
& SALAZAR & 49672 & & SAN CAYETANO & 14604 \\
& SANTIAGO & 17189 & & VILLA DEL ROSARIO & 10107 \\
& VILLA CARO & 39363 & SUROCCIDENTAL & CÁCOTA & 14197 \\
NORTE & ABREGO & 145690 & & CHITAGÁ & 117848 \\
& CÁCHIRA & 62260 & & LABATECA & 26822 \\
& CONVENCIÓN & 94249 & & MUTISCUA & 15316 \\
& EL CARMEN & 173191 & & PAMPLONA & 29389 \\
& HACARÍ & 41213 & & PAMPLONITA & 17570 \\
& LA ESPERANZA & 65828 & & SILOS & 38543 \\
& LA PLAYA & 25909 & SURORIENTAL & BOCHALEMA & 17941 \\
& OCAÑA & 49853 & & CHINÁCOTA & 16556 \\
& SAN CALIXTO & 39435 & & DURANIA & 17205 \\
TEORAMA & 93011 & & HERRÁN & 11699 \\
& TECIDENTAL & & RAGONVALIA & 10324 \\
& BUCARASICA & 27427 & & TOLEDO & 150742 \\
& EL TARRA & 71156 & & & \\
& SARDINATA & 144685 & & & \\
& TIBÚ & 267171 & & &
\end{tabular}

Fuente: Gobernación Norte de Santander, SIAT - Corponor.

Figura 2. Subregiones del departamento Norte de Santander.

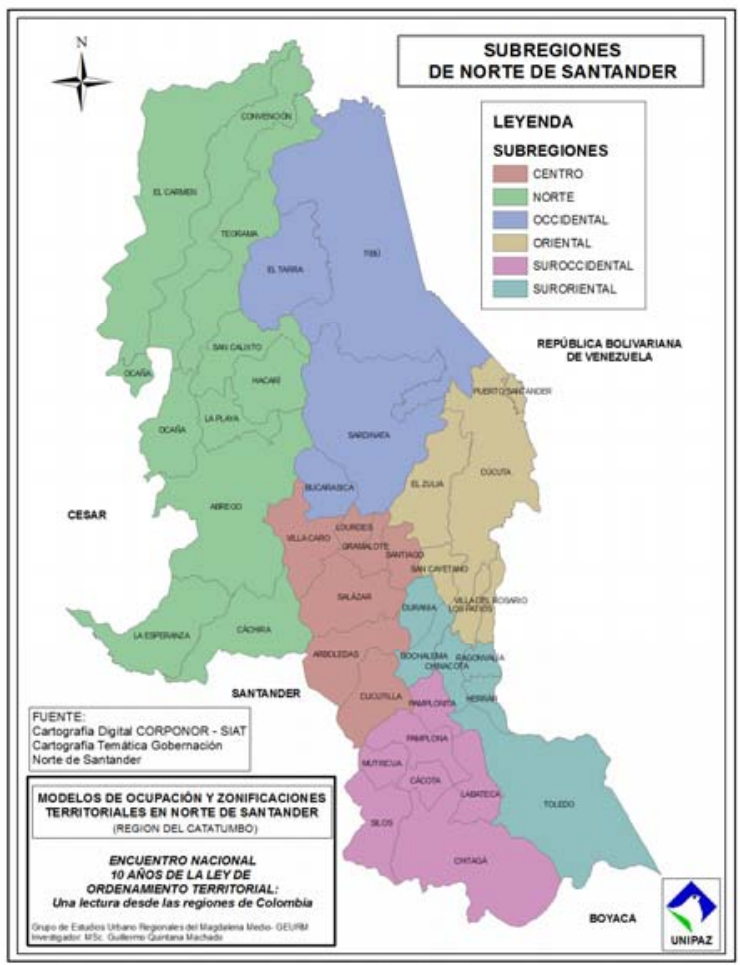

Fuente: Elaboración propia, (con base en cartografía CORPONOR - SIAT). 
Figura 3. Mapa de División Político Administrativa del departamento Norte de Santander.

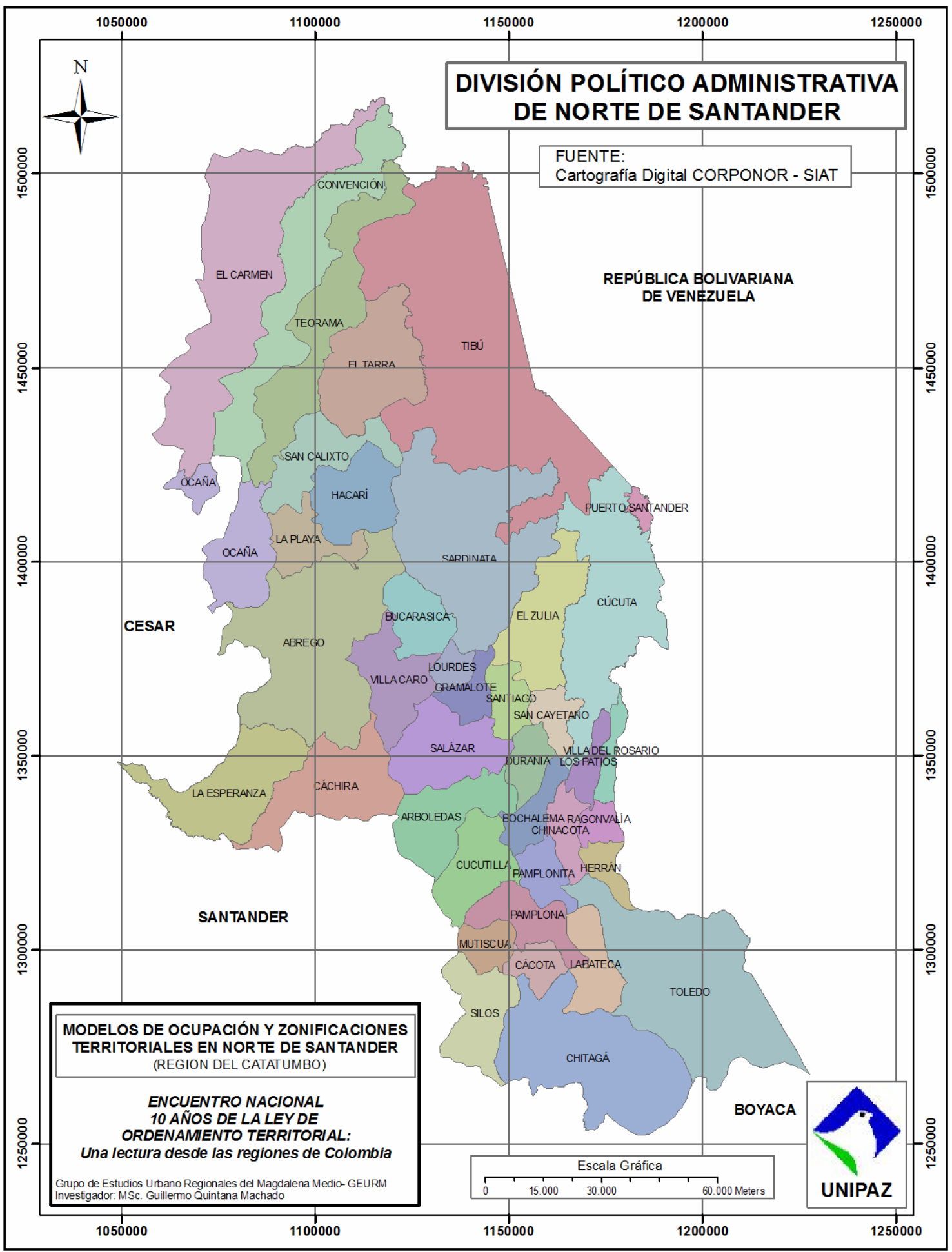

Fuente: Elaboración propia, (con base en cartografía CORPONOR - SIAT). 


\subsection{Los Ordenamientos Territoriales municipales}

En el siguiente cuadro se expresa la relación de municipios del departamento que han emprendido revisiones a sus ordenamientos territoriales, así como la fecha de adopción de los mismos y las iniciativas de planes parciales.

Tabla 2. Estado actual de OT municipales, fecha de adopción e iniciativas en planes parciales.

\begin{tabular}{|c|c|c|c|c|c|c|}
\hline MUNICIPIO & TIPO OT & $\begin{array}{c}\text { FECHA } \\
\text { ADOPCIÓN * }\end{array}$ & $\begin{array}{c}\text { AÑOS DE } \\
\text { ADOPTADO }\end{array}$ & REVISIÓN & $\begin{array}{c}\text { PLANES } \\
\text { PARCIALES }\end{array}$ & TIPO DE PLAN PARCIAL \\
\hline ABREGO & PBOT & 3-Abr-2001 & 6 & $\mathrm{x}$ & & \\
\hline ARBOLEDAS & EOT & 31-May-2003 & 4 & & 1 & Desarrollo en suelo de expansión urbana. \\
\hline BOCHALEMA & EOT & 26-Feb-2004 & 4 & & & \\
\hline BUCARASICA & EOT & 10-Dic-2000 & 7 & & & \\
\hline CÁCHIRA & EOT & 8-Dic-2000 & 7 & & & \\
\hline CÁCOTA & EOT & 23-Mar-2002 & 6 & & & \\
\hline CHINACOTA & EOT & 10-May-2003 & 4 & $x$ & & \\
\hline CHITAGÁ & EOT & 21-Jun-2000 & 7 & & & \\
\hline CONVENCIÓN & EOT & 7-Jun-2004 & 3 & & & \\
\hline CÚCUTA & РOT & 17-Ene-2001 & 7 & & 1 & Desarrollo en suelo de expansión urbana. \\
\hline CUCUTILLA & EOT & 23-Jun-2003 & 4 & & & \\
\hline DURANIA & EOT & 10-Dic-2003 & 4 & & & \\
\hline EL CARMEN & EOT & 24-Dic-2003 & 4 & & & \\
\hline EL TARRA & EOT & 20-Feb-2004 & 4 & & & \\
\hline EL ZULIA & EOT & 2-Oct-2000 & 7 & & & \\
\hline GRAMALOTE & EOT & 24-Jun-2002 & 5 & & & \\
\hline HACARÍ & EOT & 8-Abr-2001 & 6 & & & \\
\hline HERRÁN & EOT & 2-May-2002 & 5 & & 1 & Macroproyecto de reasentamiento. \\
\hline LA ESPERANZA & EOT & 29-May-2002 & 5 & & & \\
\hline LA PLAYA DE BELEN & EOT & 30-May-2000 & 7 & & & \\
\hline LABATECA & EOT & 5-Sep-2003 & 4 & & & \\
\hline LOS PATIOS & PBOT & 8-Dic-2000 & 7 & & & \\
\hline LOURDES & EOT & 9-Sep-2001 & 6 & & & \\
\hline MUTISCUA & EOT & 22-Mar-2003 & 5 & & & \\
\hline OCAÑA & PBOT & 6-Sep-2002 & 5 & $\mathrm{X}$ & 9 & $\begin{array}{l}\text { (6) En suelos de expansión urbana, } \\
\text { (3) desarrollo urbano. }\end{array}$ \\
\hline PAMPLONA & PBOT & 31-Ago-2002 & 5 & & & \\
\hline PAMPLONITA & EOT & 25-Feb-2003 & 5 & & & \\
\hline PUERTO SANTANDER & EOT & 7-Dic-2000 & 7 & & & \\
\hline RAGONVALIA & EOT & 28-Feb-2003 & 5 & & 1 & Desarrollo en suelo de expansión urbana. \\
\hline SALAZAR & EOT & 25-Ene-2003 & 5 & & & \\
\hline SAN CALIXTO & EOT & 17-Sep-2001 & 6 & & & \\
\hline SAN CAYETANO & EOT & 12-Jul-2000 & 7 & & & \\
\hline SANTIAGO & EOT & 19-Sep-2000 & 7 & & & \\
\hline SARDINATA & EOT & 16-Feb-2002 & 6 & & & \\
\hline SILOS & EOT & 15-Dic-2000 & 7 & & & \\
\hline TEORAMA & EOT & 11-Sep-2000 & 7 & & & \\
\hline TIBÚ & PBOT & 6-Dic-2000 & 7 & $x$ & & \\
\hline TOLEDO & EOT & 22-Ago-2001 & 6 & & & \\
\hline VILLA CARO & EOT & 25-Ago-2001 & 6 & & & \\
\hline VILLA DEL ROSARIO & PBOT & 28-Dic-2000 & 7 & & & \\
\hline
\end{tabular}

En el cuadro anterior se observa que un $35 \%$, de los municipios de Norte de Santander llevan más de 7 años de ordenamiento territorial municipal, aproximadamente un $63 \%$ realizó su 
adopción entre cuatro y seis años atrás, siendo solamente el municipio de La Playa el que adoptó su EOT hace tres años. Esto muestra que la mayoría de los municipios del departamento requieren de la iniciación del proceso de revisión de sus ordenamientos territoriales, sin embargo de los 40 municipios solo cuatro, Tibú, Abrego, Ocaña y Chinácota, han emprendido procesos de revisión a sus ordenamientos territoriales municipales.

Por otra parte, en lo relacionado con el desarrollo de planes parciales, han cursado su procedimiento para evaluación ante la autoridad ambiental CORPONOR, un total de 13 planes parciales, de los cuales nueve (9) son para desarrollos de expansión urbana, y los demás corresponden a desarrollo urbano y un proyecto de reasentamiento. De estos trece planes parciales nueve fueron adelantados por el municipio de Ocaña, y los restantes por los municipios de Arboledas, Cúcuta, Herrán y Ragonvalia.

\section{Contexto general de la región del Catatumbo.}

\section{$2.1 \quad$ Aspectos Geográficos - Territoriales}

Ésta región está ubicada al Norte del Departamento Norte de Santander, comprendiendo principalmente los municipios de El Carmen, Convención, Teorama, San Calixto, El Tarra, Tibú y otros en menor proporción que no se abordarán en el presente documento. El Catatumbo tiene una geografía densa, montañosa y boscosa, de complejo acceso, con restringidas redes viales, sus componentes climáticos y fisiográficos permiten el desarrollo de una abundante oferta de flora y fauna ligada a una red hídrica de gran riqueza y una considerable oferta minera y de hidrocarburos.

En la región se presentan fuertes zonas de colonización (pequeña propiedad), que por una parte son comunidades que demandan acceso a tierra y regularización de tenencia y por otro representan una afectación directa a las zonas de reserva de la región.

\subsection{Aspectos Sociopolíticos}

El Catatumbo nortesantandereano constituye una región que se caracteriza por una compleja dinámica territorial, que a través de su historia ha sido afectada por un gran número de factores asociados con la violencia por el conflicto armado, el narcotráfico asociado a los cultivos de uso ilícito, y conexo a estos entre otros, se presentan las violaciones al DIH y a los DDHH.

Esta situación en el transcurrir de los últimos diez años no se ha alterado estructuralmente, es decir, han cambiado las intensidades y las tipificaciones de la violencia, pero en esencia lo que ocurre son transiciones y cambios de poder territorial, que sin duda alguna demuestran la ingobernabilidad de este territorio por parte de las Entidades Territoriales en todos sus niveles. 


\section{Zonificaciones y modelos territoriales en la región del Catatumbo.}

En la región del Catatumbo nortesantandereano se evidencia la superposición de diferentes modelos de ocupación territorial y distintos niveles de zonificación y manejo del uso del suelo, de mayor a menor jerarquía podemos encontrar los siguientes: Zonas de Reserva Forestal al nivel Nacional con competencia en el Ministerio de Ambiente Vivienda y Desarrollo Territorial MAVDT, Parques Nacionales Naturales al Nivel Nacional con competencia en la Unidad Especial de Parques Nacionales Naturales - UAEPNN, Territorios étnicos (Resguardos Indígenas) al nivel Nacional - Regional con competencia en la Dirección de Etnias del Ministerio del Interior y Justicia, y los Esquemas, Planes Básicos y Planes de Ordenamiento Territorial al Nivel Municipal con competencia en los Concejos Municipales.

\subsection{Las zonas de reserva forestal en Colombia}

La Ley 2 de 1959 crea "Para el desarrollo de la economía forestal y protección de los suelos, las aguas y la vida silvestre, se establecen con carácter de "Zonas Forestales Protectoras" y "Bosques de Interés General"........, las siguientes zonas de reserva forestal", así: Sierra Nevada de Santa Marta, Serranía de Los Motilones, Sierra del Cocuy, Río Magdalena, Costa Pacífica, Región Central y Amazonia, que en conjunto tenían una cobertura aproximada de $65.7^{3}$ millones de hectáreas

Tabla 3. Áreas de Reservas Forestales (Ley $2^{a}$ de 1959 y Decreto 111/59) - Áreas Sustraídas y actuales.

\begin{tabular}{cccc}
\hline Reserva Forestal & Área declarada (ha) & $\begin{array}{c}\text { Área sustraída } \\
\text { (ha) }\end{array}$ & $\begin{array}{c}\text { Área actual } \\
\text { (ha) }\end{array}$ \\
Amazonía & $43,959,737$ & $6,115,213$ & $37,844,524$ \\
Central & $1,621,180$ & 77,474 & $1,543,707$ \\
Cocuy & 869,458 & 139,069 & 730,388 \\
Pacífico & $11,155,214$ & $3,144,603$ & $8,010,612$ \\
Río Magdalena & $5,823,468$ & $3,667,878$ & $2,155,591$ \\
Serranía de los Motilones & 998,581 & 445,890 & 552,691 \\
Sierra Nevada de Santa & 852,683 & 313,468 & 539,215 \\
Marta & & & \\
TOTAL & $\mathbf{6 5 , 2 8 0 , 3 2 1}$ & $\mathbf{1 3 , 9 0 3 , 5 9 5}$ & $\mathbf{5 1 , 3 7 6 , 7 2 8}$ \\
\hline
\end{tabular}

FUENTE: Proyecto Reservas Forestales (Convenio Minambiente - IDEAM, 097/01).

\section{Zonas de Reserva Forestal Serranía de Los Motilones}

La ZRF de la Serranía de Los Motilones, está comprendida dentro de los siguientes linderos generales, según el literal e) del artículo 1 de la Ley 2 de 1959: "por el oriente, la línea de frontera con la República de Venezuela y el límite entre los departamentos de Cesar y la

\footnotetext{
${ }^{2}$ Congreso de Colombia, Ley 2 de 1959, Artículo 1.

${ }^{3}$ Ministerio del Medio Ambiente, Dirección General de Ecosistemas, Grupo Bosques; Reservas forestales del orden nacional, compilador Raimundo Tamayo, 2004.
} 
Guajira se sigue una distancia de $20 \mathrm{~km}$.; se continúa al oeste de la frontera entre Colombia y Venezuela, desde el límite norte descrito en una línea paralela a $20 \mathrm{Km}$ hasta la intersección con la longitud $73^{\circ} 30^{\prime}$ y de allí hacia el sur hasta su intersección con latitud norte $8^{\circ} 30^{\prime}$ siguiendo por este paralelo hasta encontrar la frontera con Venezuela".

Sobre la Zona de Reserva Forestal de la Serranía de los Motilones existen territorios indígenas, los resguardos Motilón - Barí y el Catalaura, los cuales ocupan un área aproximada a 191000 ha, lo cual equivale a un 35\% del área total actual de la ZRF.

Adicionalmente dentro de la ZRF se declaró el Parque Nacional Natural Catatumbo - Barí, con el objetivo de preservar los relictos de bosque húmedo tropical y toda la biodiversidad asociada a este ecosistema, presentes en la región norte del departamento Norte de Santander. Según el IDEAM, legalmente el Parque se sobrepone con la Reserva tan solo en $42.947 \mathrm{ha}^{4}$, lo cual representa casi un $8 \%$ del área en Reserva Forestal.

El ministerio de Ambiente hoy MAVDT, citando un estudio de consultoría realizado por la firma Ifcaya Ltda. en el año de 1989, relaciona que una solicitud de sustracción a la Reserva Forestal presentada al Inderena, determina que dadas las condiciones, especialmente en cuanto a la intervención antrópica y uso actual del suelo, escasamente 175.000 hectáreas deben permanecer bajo el régimen de la Ley 2 de 1959, distribuidas en dos sectores: uno de 160.200 hectáreas correspondiente al límite internacional con Venezuela y otro de 11.600 hectáreas localizadas entre los límites de los departamentos de Cesar y Norte de Santander.

Según el IDEAM, el estado actual de la Reserva Forestal, presenta las siguientes características; "la cobertura boscosa alcanza la no despreciable superficie de $285.220 \mathrm{Ha}$ correspondientes a más del 55\% de la Reserva, sin embargo, la mayoría corresponde a bosques fragmentados del piso andino $(163.368 \mathrm{Ha})$ situados principalmente en los límites del Parque Nacional; en estado natural se encuentran aún 121.853 Ha sobre algunas zonas contiguas al área protegida y sobre territorios de difícil acceso",5.

\footnotetext{
${ }^{4}$ IDEAM, Subdirección de Ecosistemas e Información Ambiental; Reservas Forestales ley $2^{\mathrm{a}}$ de 1959, Diagnóstico Estado Actual, compilador Ing. Robert León Cruz.

${ }^{5}$ Idem., pág. 6.
} 
Architecture, City, and Environment
Arquitectura, Ciudad y Entorno

Figura 4. Mapa de la Zona de Reserva Forestal Serranía de Los Motilones.

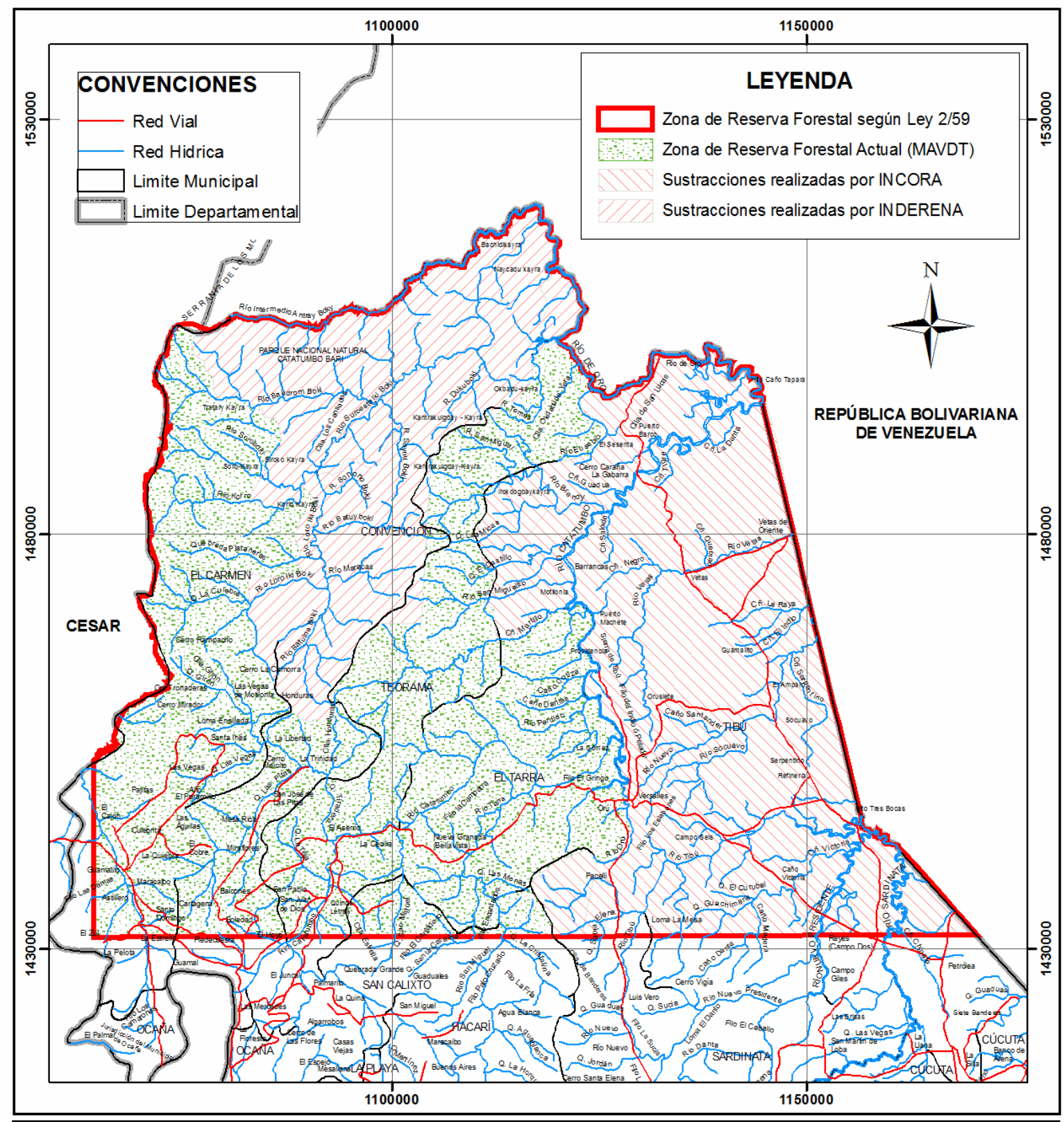

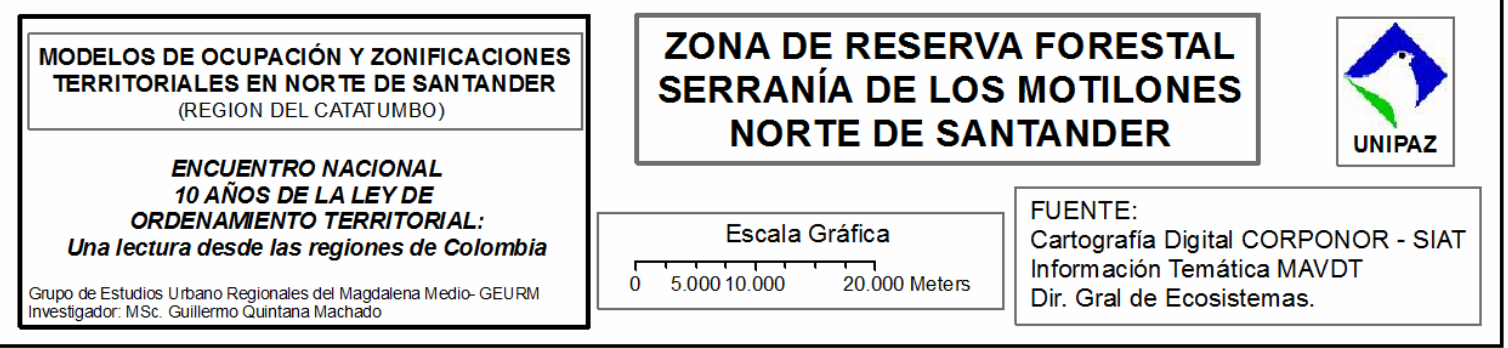

Fuente: Elaboración propia, (con base en cartografía CORPONOR - SIAT, MAVDT). 


\subsection{Parques Nacionales Naturales}

En el nivel nacional el Sistema de Parque Nacionales Naturales es manejado y administrado por la Unidad Administrativa Especial de Parques Nacionales Naturales - UAESPNN ${ }^{6}$, la cual es una dependencia del Ministerio de Ambiente Vivienda y Desarrollo Territorial, con autonomía administrativa y financiera. El sistema de Parques Nacionales Naturales contribuye a la conformación y consolidación del Sistema Nacional de Áreas Protegidas ${ }^{7}$ y a la coordinación e implementación de políticas, planes, programas, normas y procedimientos relacionados con el SINAP.

Se entiende por Parque Nacional Natural, "Área de extensión que permita su autorregulación ecológica y cuyos ecosistemas en general no han sido alterados sustancialmente por la explotación u ocupación humana, y donde las especies vegetales de animales, complejos geomorfológicos y manifestaciones históricas o culturales tiene valor científico, educativo, estético y recreativo nacional y para su perpetuación se somete a un régimen adecuado de manejo"8.

En Colombia existen 53 áreas naturales pertenecientes al Sistema de Parques Nacionales Naturales, de las cuales 3 se encuentran ubicadas en el departamento Norte de Santander, así; el Parque Nacional Catatumbo Barí, Área Nacional única Los Estoraques y el Parque Nacional Tamá, el cual colinda con un área protegida en territorio Venezolano.

\section{Parque Nacional Natural Catatumbo Barí}

En este escrito se hará especial referencia al PNN Catatumbo Barí, el cual fue declarado Parque Nacional Natural mediante Resolución Ejecutiva No. 121 del 21 de Octubre de 1989; Según la Corporación Ambiental de la Frontera Nororiental - CORPONOR, el parque "constituye uno de los más bellos enclaves de bosque húmedo tropical. Su extensión es de 158.125 ha distribuidas en los siguientes municipios del Departamento Norte de Santander: Convención (35.1\%), El Carmen (41.2\%), Tibú (1.9\%) y Teorama (21.8\%). Tiene alturas que van desde los 200 hasta los 1.800 m.s.n.m., las formas terrestres del Parque varían de onduladas a fuertemente quebradas, con pendientes que oscilan entre $30 \%$ a $50 \%$. La precipitación anual se calcula en 1.200 hasta $2.000 \mathrm{~mm}$. La temperatura promedio anual es de $28.5^{\circ} \mathrm{C}$ en las partes más bajas a $17^{\circ} \mathrm{C}$ en las cimas de cerros que alcanzan los 2.000 m.s.n.m. Todas las corrientes que se originan en el parque hacen parte de la hoya hidrográfica del Río Catatumbo". 9

\footnotetext{
${ }^{6}$ Congreso de la República de Colombia. Ley 489 de 1998, artículo 54, Literal j.

${ }^{7}$ El sistema Nacional de Áreas Protegidas, son el conjunto de áreas naturales protegidas (de carácter público, privado y comunitario en los niveles de gestión pública nacional, regional o local), actores sociales y las estrategias e instrumentos de gestión que los articulan y congregan para contribuir como un todo al cumplimiento de los objetivos de conservación que el país persigue.

${ }^{8}$ Presidencia de la República de Colombia. Decreto 2811 de 1974, artículo 329, literal a.

${ }_{9}^{9}$ Corporación Ambiental de la Frontera Nororiental CORPONOR, Plan de Gestión Ambiental Regional, San José de Cúcuta, 2002.
} 
Figura 5. Mapa del Parque Nacional Natural Catatumbo Barí.

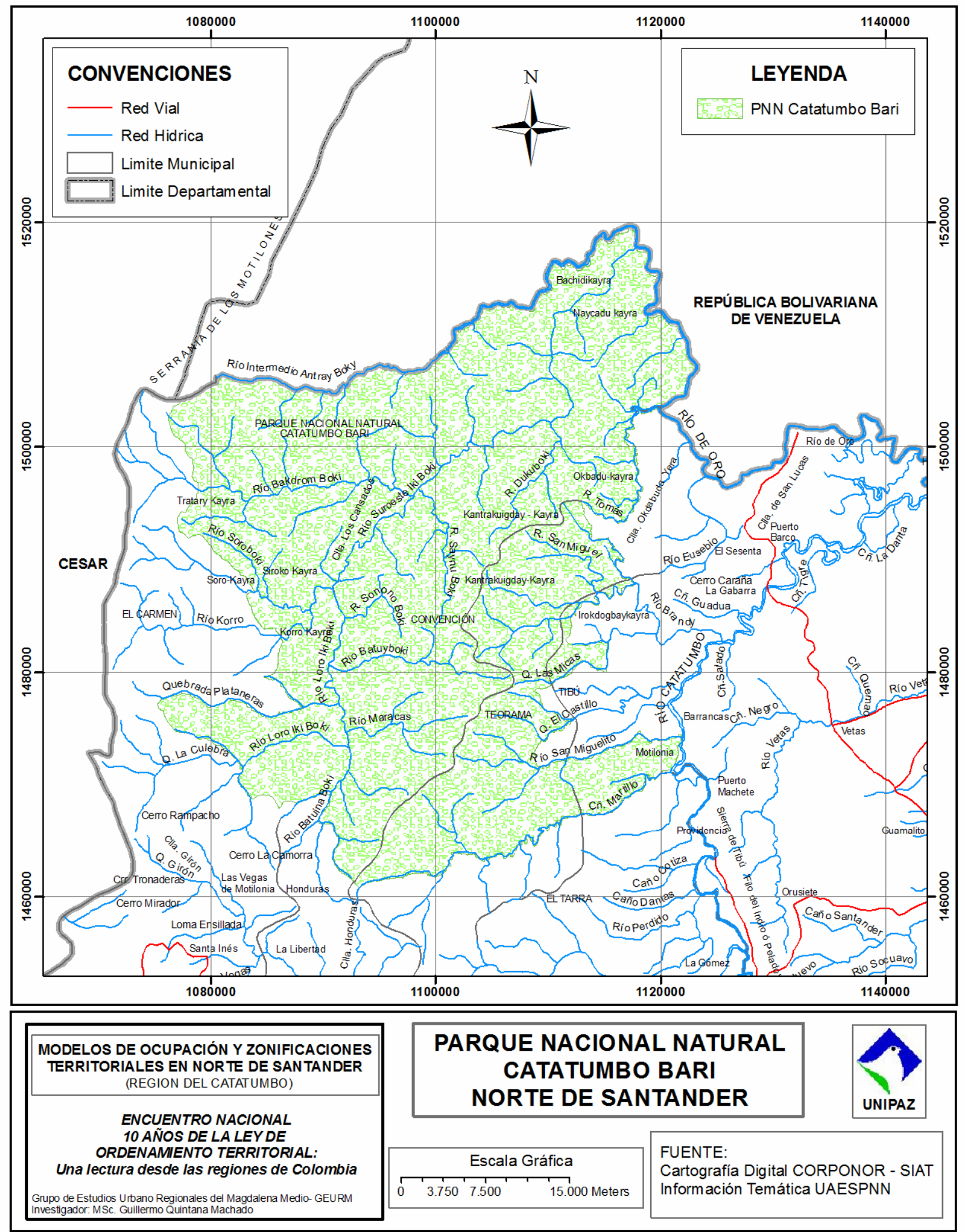

Fuente: Elaboración propia, (con base en cartografía CORPONOR - SIAT, UAESPNN). 


\subsection{Territorios étnicos indígenas.}

Los territorios étnicos indígenas en Colombia comienzan a recibir un tratamiento especial desde el punto de vista jurídico - territorial, después de la Constitución Política de 1991, en la cual se contempla la posibilidad de conformación de Entidades Territoriales Indígenas ETI, el artículo 329 de la CP, versa lo siguiente;

ARTICULO 329 de la CONSTITUCIÓN POLÍTICA DE COLOMBIA.

La conformación de las entidades territoriales indígenas se hará con sujeción a lo dispuesto en la Ley Orgánica de Ordenamiento Territorial, y su delimitación se hará por el Gobierno Nacional, con participación de los representantes de las comunidades indígenas, previo concepto de la Comisión de Ordenamiento Territorial.

Los resguardos son de propiedad colectiva y no enajenable.

La ley definirá las relaciones y la coordinación de estas entidades con aquellas de las cuales formen parte.

PARAGRAFO. En el caso de un territorio indígena que comprenda el territorio de dos o más departamentos, su administración se hará por los consejos indígenas en coordinación con los gobernadores de los respectivos departamentos. En caso de que este territorio decida constituirse como entidad territorial, se hará con el cumplimiento de los requisitos establecidos en el inciso primero de este artículo.

También se establece en el marco constitucional, que los territorios indígenas estarán gobernados por consejos conformados y reglamentados según los usos y costumbres de sus comunidades y que "la explotación de los recursos naturales se hará sin desmedro de la integridad cultural, social y económica de las comunidades indígenas. En las decisiones que se adopten respecto de dicha explotación, el Gobierno propiciará la participación de los representantes de las respectivas comunidades"10.

Existen otros referentes normativos no menos importantes que hacen alusión a territorios étnicos, como son la Ley 70 de 1993, Ley 160 de 1994, Ley 388 de 1997, entre otros, que no se profundizarán en este escrito.

En este sentido es de tener en cuenta que la existencia de territorios étnicos constituidos o no, o la presencia de comunidades étnicas, implican por parte del Estado un tratamiento particular, en el cual se concilie el ordenamiento municipal local con los Planes de Vida de dichos grupos, en el caso de Norte de Santander se hará referencia específicamente al pueblo indígena Barí.

\section{Resguardo Indígena Motilón - Barí}

En la región del Catatumbo Nortesantandereano, específicamente en jurisdicción del Parque Nacional Natural Motilón Barí existen dos territorios indígenas, así: el resguardo indígena Motilón - Barí localizada en los municipios de El Carmen, Convención y Teorama con una extensión de 101.742 ha de acuerdo a las resolución Incora 101 del 2 de Octubre de 1974, por la cual se constituye el territorio como reserva especial destinada a la población Motilón Barí, un área de terreno con un área aproximadamente de 83.000 ha, dicha área fue sustraída

\footnotetext{
${ }^{10}$ Constitución Política de Colombia de 1991, Artículo 330.
} 
previamente de la Zona de Reserva Forestal de la Serranía de los Motilones (Ley 2 de 1959), mediante Acuerdo No. 016 de septiembre 8 de 1.972, del INDERENA.

En el año de 1988, se expide la resolución 102 del 28 de Noviembre, por la cual se conforma oficialmente el resguardo Motilón Barí, sin embargo la situación de la ocupación de los terrenos declarados como reserva indígena mediante la resolución 101 del año 1974 cambió radicalmente, encontrándose invadidas por colonos un área aproximada de 26.000 ha. Por lo tanto se adicionaron a la conformación del resguardo en 1988, un área aproximada a 52.000 ha de terrenos baldíos, como compensación por los terrenos colonizados en el área reservada inicialmente.

Según el PBOT del municipio de Tibú:

"En su parte resolutoria (Resolución No. 102 de 26.11.88) establece un área de 108.900 Hectáreas para el Resguardo Motilón Barí ( De las cuales 56.330 Has. Correspondían a la Reserva Indígena y 52. 570 Has. A baldíos contiguos a la reserva en mención)."11

Por consiguiente, en suma el resguardo Motilón Barí cuenta según sus documentos de constitución con un área de 108.900 ha, las cuales se encuentran dentro de la jurisdicción del Parque Nacional Natural.

\section{Resguardo Indígena Catalaura}

El resguardo Indígena Catalaura está ubicado en la parte sur oriental del Resguardo Motilón Barí, en jurisdicción de los municipios de Teorama y Tibú, fue constituido mediante resolución Incora No. 105 de Diciembre 15 de I.981, la cual modificó lo dispuesto en la resolución de la misma entidad No. 145 del 24 de Julio de 1967, por tanto se declaran terrenos con un área de 13.300 ha, para una colonización especial a favor de la comunidad Indígena Motilón de Catalaura.

\footnotetext{
${ }^{11}$ Municipio de Tibú, Plan Básico de Ordenamiento Territorial municipal, Capítulo V - La Etnia Barí dentro del contexto del Plan Básico de Ordenamiento Territorial Municipal, 2000.
} 
Figura 6. Mapa de Territorios Étnicos Indígenas en la región del Catatumbo - Norte de Santander

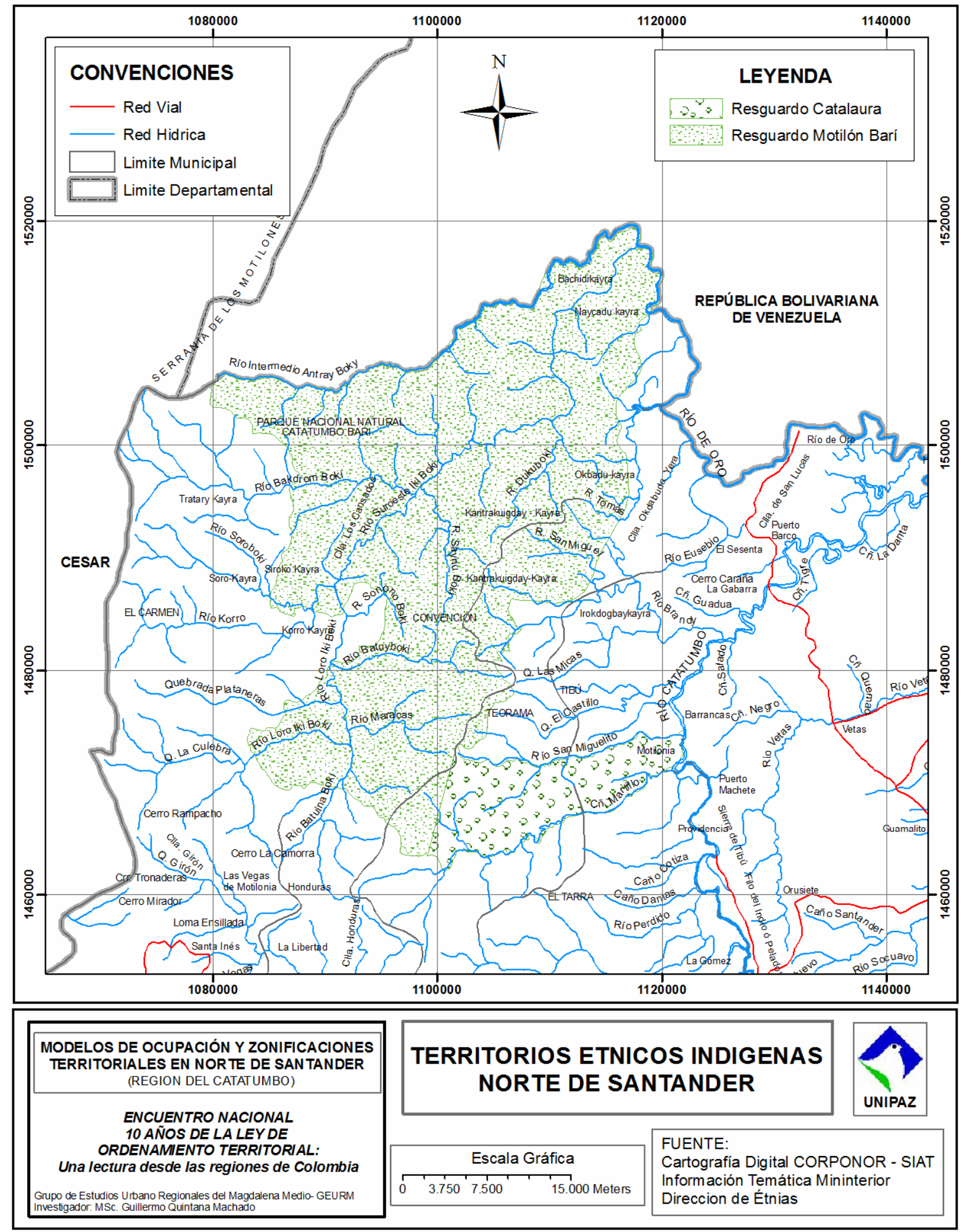

Fuente: Elaboración propia, (con base en cartografía CORPONOR - SIAT). 


\subsection{Modelos de ocupación territorial al nivel municipal.}

Los modelos de zonificación ambiental de los Esquemas y planes básicos de ordenamiento Territorial de los municipios de la región del Catatumbo, no están totalmente armonizados entre sí, en algunos casos, municipios desarrollan diferentes tipos de producción económica, que varían desde agricultura tradicional hasta sistemas agrosilvopastoriles, todo esto en corredores con la misma vocación ambiental, pero pertenecientes a diferentes entidades territoriales.

Existen directrices de carácter general, en las diferentes jerarquías territoriales, aún así la realidad sobrepasa la norma cuando se trata las intervenciones antrópicas sobre áreas protegidas o territorios especiales. Por otra parte por más que las administraciones municipales hagan esfuerzos normativos en el orden local para acoger las directrices nacionales y locales, no es suficiente para la armonización de sus ordenamientos territoriales locales, y principalmente para hacer efectivos los modelos de organización y desarrollo municipal.

Al analizar los modelos de ocupación territorial municipales en la región del Catatumbo, se observa una fragmentación territorial, con diferentes niveles de conflicto sobre cada una de las clasificaciones, zonificaciones y administraciones especiales del territorio (Parque Nacional Natural, Territorio étnico, Zona de Reserva Forestal), como se podrá observar más adelante. A continuación se expresan las unidades de zonificación para los municipios de la zona de estudio, así; Convención, El Carmen, El Tarra, San Calixto, Teorama y Tibú.

Figura 7. Porcentaje de unidades de zonificación por municipio.
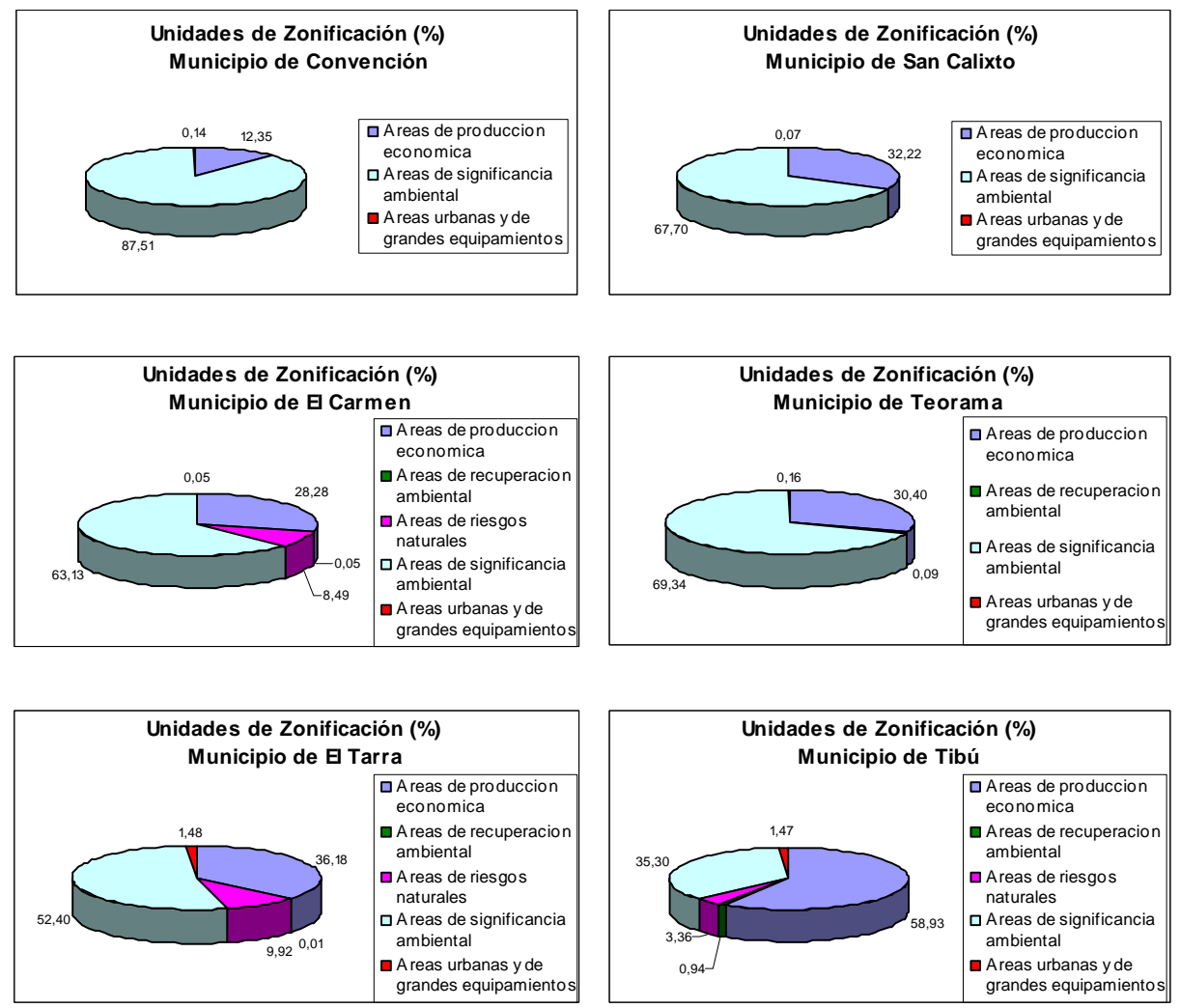

Fuente: Elaboración propia, (con base en datos CORPONOR - SIAT y Esquemas de Ordenamiento Territorial). 
Como se puede observar en la figura 7, los municipios de Convención, San Calixto, El Carmen y Teorama tienen zonificado su territorio en un alto porcentaje, entre $63 \%$ y $87 \%$, identificado como Áreas de Significancia Ambiental, con un menor porcentaje se ubica El Tarra con un $52 \%$, y por último se encuentra Tibú, el cual por razones económicas y políticas su territorio fue sustraído de la Zona de Reserva Forestal, establecida mediante Ley 2/59, y su PBOT estableció casi el 60\% de su territorio para Áreas de Producción Económica.

El promedio de territorio destinado por el resto de municipios para Áreas de Producción Económica es cercano al 30\%, excepto Convención que solamente definió casi un 13\% en esta unidad de zonificación.

Las otras unidades de zonificación como Áreas de Recuperación Ambiental y Áreas urbanas y de Grandes Equipamientos representan porcentajes muy bajos, excepto las Áreas de Riesgos Naturales, las cuales alcanzan valores significativos en El Carmen y El Tarra, con valores cercanos al $10 \%$ y un valor no despreciable en Tibú de casi $4 \%$.

En la tabla a continuación se muestran las áreas de las zonificaciones territoriales municipales con respecto a las Áreas Especiales (Parque Nacional Natural, Resguardos Indígenas, Zona de Reserva Forestal), en ella se puede observar que en general todos los municipios referidos articularon sus ordenamientos territoriales a los lineamientos de Parque Nacional Natural y los Resguardos Indígenas, sin que esto en la práctica signifique el efectivo cumplimiento de las normas. Por otra parte en la Zona de Reserva Forestal se ven unas áreas que corresponden a producción económica, que corresponden a zonas de colonización periféricas al PNN y al resguardo Motilón Barí, tal como se observa en la Figura 9.

La zonificación correspondiente a las Áreas de Recuperación Ambiental, se encuentran en el municipio de Tibú en jurisdicción del resguardo Indígena Catalaura, y las Áreas de Riesgo Natural en el municipio de El Carmen dentro de la Zona de Reserva Forestal. 
Tabla 4. Zonificaciones Municipales vs Áreas Especiales.

\begin{tabular}{|c|c|c|c|c|c|c|}
\hline \multirow{3}{*}{ MUNICIPIO } & AREA & & & & & \\
\hline & $\begin{array}{r}\text { ESPECIAL } \\
\text { RESGUARDO }\end{array}$ & APE & ARA & ARN & ASA & TOTAL \\
\hline & M.B. & & & & 48924,37 & 48924,37 \\
\hline \multirow[t]{2}{*}{ CONVENCION } & ZRF & 8261,21 & & & 16689,46 & 24950,67 \\
\hline & PNN-CTBI & & & & 58572,52 & 58572,52 \\
\hline \multicolumn{7}{|l|}{ Total } \\
\hline \multirow[t]{3}{*}{ Convención } & & 8261,21 & & & 124186,35 & 132447,57 \\
\hline & RESGUARDO & & & & & \\
\hline & M.B. & & & & 44646,07 & 44646,07 \\
\hline \multirow[t]{2}{*}{ EL CARMEN } & ZRF & 41672,49 & 84,88 & 9721,93 & 45917,61 & 97396,92 \\
\hline & PNN-CTBI & & & & 65009,45 & 65009,45 \\
\hline Total & & & & & & \\
\hline \multirow[t]{3}{*}{ Carmen } & & 41672,49 & 84,88 & 9721,93 & 155573,13 & 207052,44 \\
\hline & RESGUARDO & & & & & \\
\hline & M.B. & & & & 4441,42 & 4441,42 \\
\hline \multirow[t]{2}{*}{ EL TARRA } & ZRF & 25706,22 & 10,39 & 7060,89 & 33011,69 & 65789,19 \\
\hline & PNN-CTBI & & & & 4368,49 & 4368,49 \\
\hline \multicolumn{2}{|l|}{ Total El Tarra } & 25706,22 & 10,39 & 7060,89 & 41821,60 & 74599,10 \\
\hline SAN CALIXTO & ZRF & 2473,75 & & & 7083,77 & 9557,52 \\
\hline Total San & & & & & & \\
\hline \multirow{3}{*}{ Calixto } & & 2473,75 & & & 7083,77 & 9557,52 \\
\hline & RESGUARDO & & & & & \\
\hline & M.B. & & & & 20567,85 & 20567,85 \\
\hline \multirow[t]{2}{*}{ TEORAMA } & ZRF & 22243,66 & & & 59490,75 & 81734,40 \\
\hline & PNN-CTBI & & & & 30055,61 & 30055,61 \\
\hline \multirow[t]{2}{*}{ Total Teorama } & & 22243,66 & & & 110114,21 & 132357,86 \\
\hline & RESGUARDO & & & & & \\
\hline \multirow[t]{2}{*}{ TIBU } & M.B. & & & & 61,30 & 61,30 \\
\hline & PNN-CTBI & & & & 1364,59 & 1364,59 \\
\hline Total Tibú & & & & & 1425,88 & 1425,88 \\
\hline
\end{tabular}

(1) Áreas de Producción Económica, (2) Áreas de Recuperación Ambiental, (3) Áreas de Riesgos Naturales, (4) Áreas de Significancia Ambiental

Fuente: Elaboración propia, (con base en datos CORPONOR - SIAT y Esquemas de Ordenamiento Territorial). 
Figura 8. Mapa de Modelos de ocupación territorial al nivel municipal en la región del Catatumbo - Norte de Santander

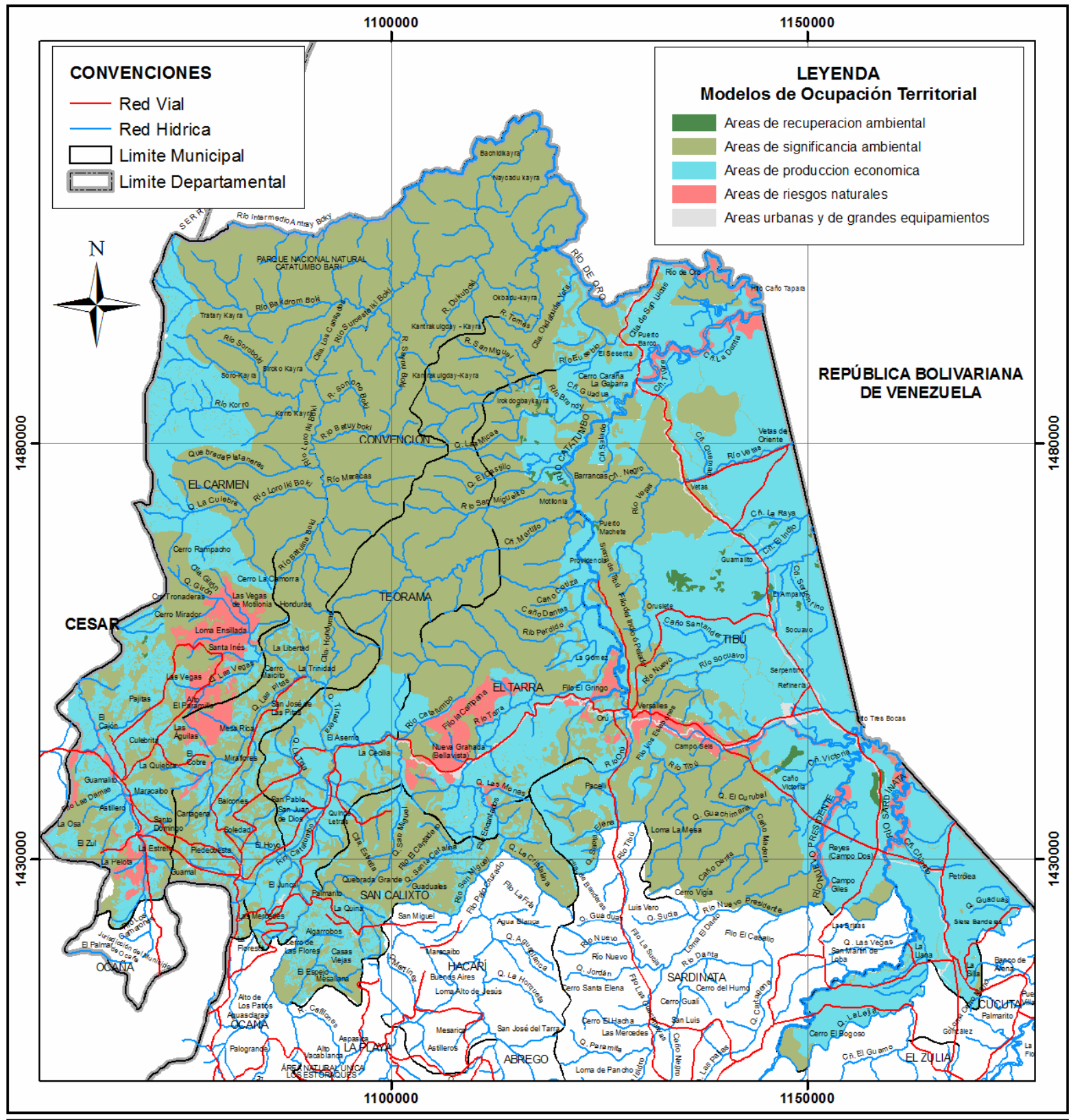

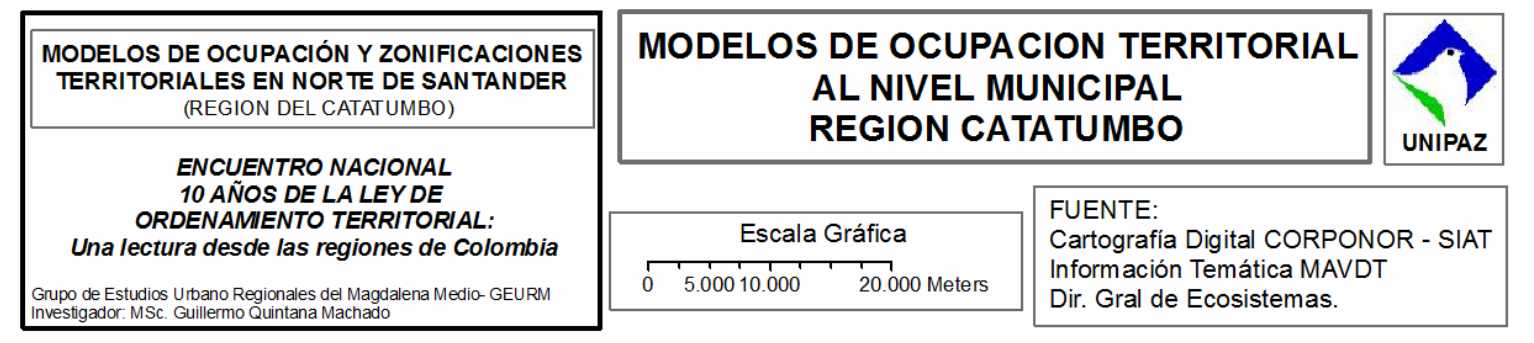

Fuente: Elaboración propia, (con base en cartografía CORPONOR - SIAT). 
Figura 9. Mapa de Modelos de ocupación y zonificaciones territoriales en la región del Catatumbo - Norte de Santander

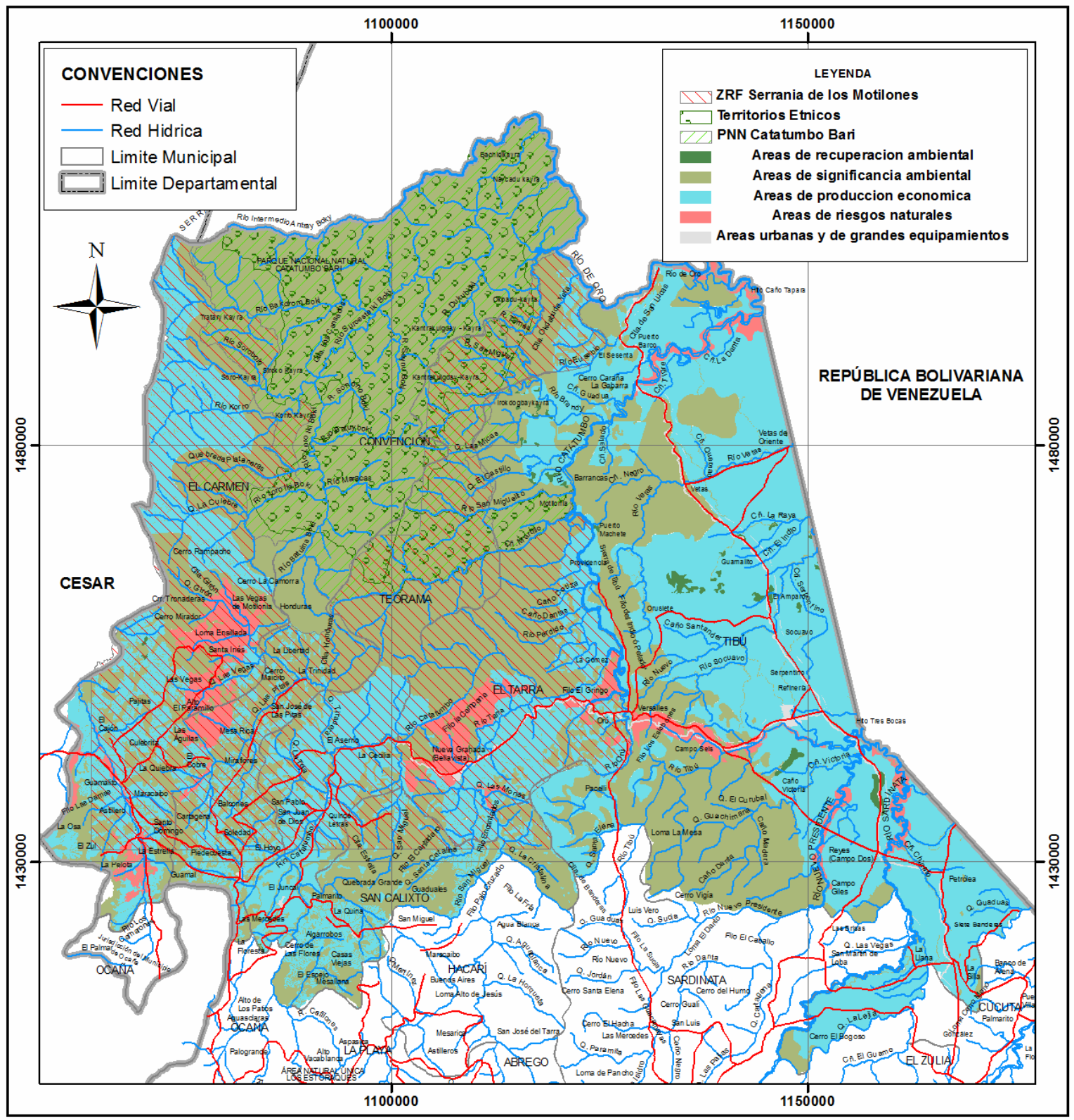

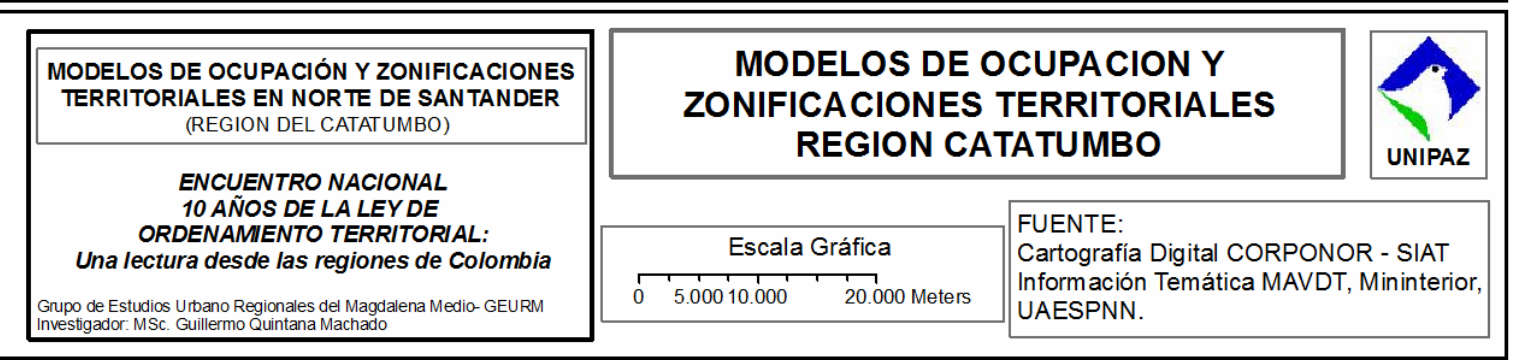

Fuente: Elaboración propia, (con base en cartografía CORPONOR - SIAT). 


\section{El catatumbo nortesantandereano; mirada integral al territorio actual}

\subsection{La institucionalidad en la región.}

Existen múltiples instituciones e instancias territoriales que tienen jurisdicción sobre la zona del Catatumbo nortesantandereano, dicha situación configura en la región una realidad compleja en cuanto a políticas y directrices de desarrollo, sumando a ello la presencia de grupos armados al margen de la ley, los cuales desde hace décadas están en confrontación por el dominio del territorio. Por tanto en la región se ha percibido durante las últimas décadas la falta de presencia estatal y la ingobernabilidad de esta región, lo cual se evidencia en las cifras de desplazamiento, y en todas las estadísticas de diferentes fuentes sobre las acciones de grupos armados en la región.

Los modelos de ocupación territorial de los municipios se ajustan principalmente a los lineamientos de carácter nacional relacionados con la preservación y conservación de áreas estratégicas como los Parques Nacionales Naturales, dado que la UAESPNN medianamente logra hacer interlocución con las diferentes alcaldías locales, en cumplimiento del rol administrativo del PNN. En lo referente a las Zonas de Reserva Forestal todas en el país han sido afectadas de procesos de colonización, y como se ha podido observar la ZRF de la Serranía de Los Motilones no es la excepción.

La situación respecto a la interrelación entre la institucionalidad municipal y las autoridades indígenas de los resguardos en su jurisdicción, es mínimo, no se incorporan elementos de los Planes de Vida de las comunidades indígenas a los componentes generales de los ordenamientos territoriales municipales.

Figura 10. Superposición de competencias institucionales.

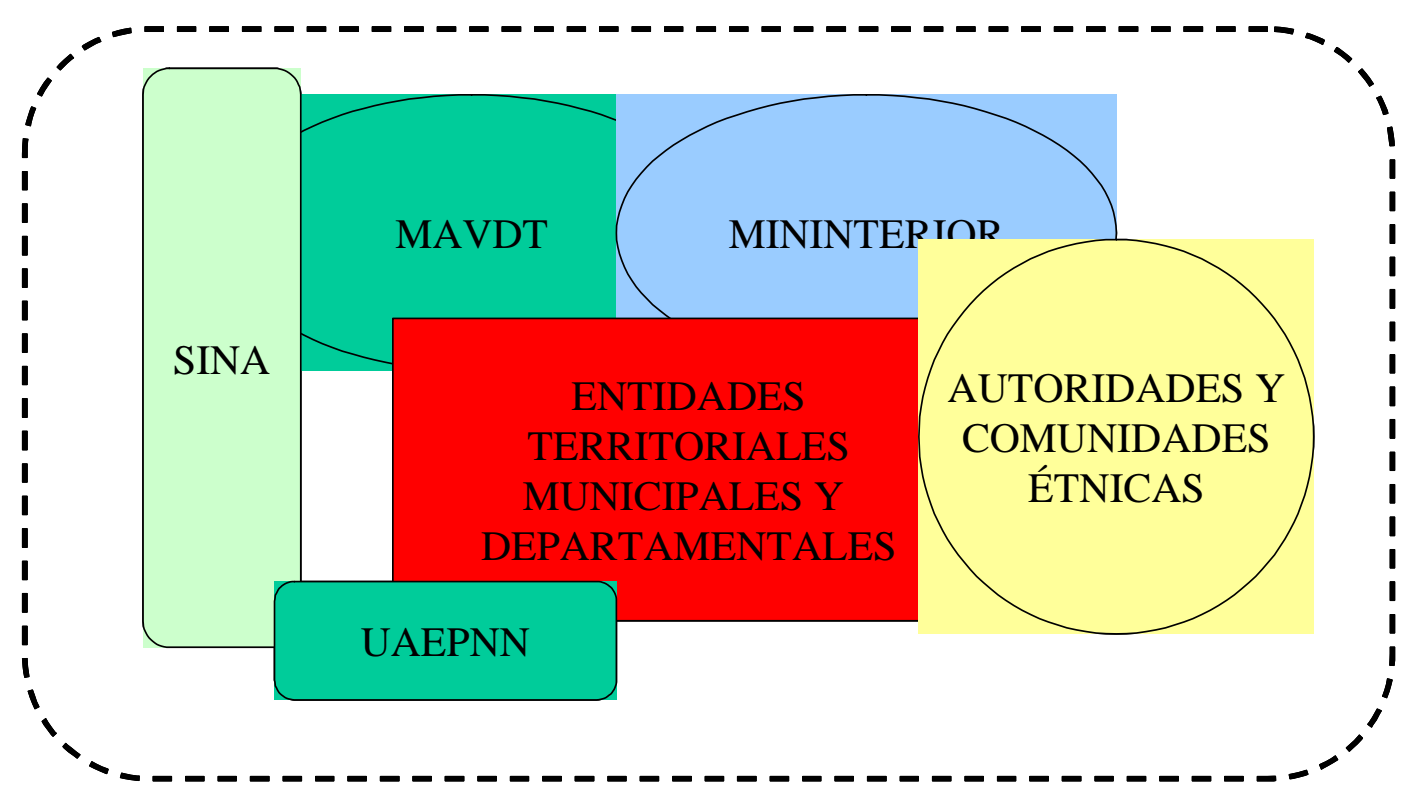

Fuente: Elaboración propia. 


\subsection{Algunos retos para el ordenamiento territorial en los distintos niveles e instancias} territoriales.

A continuación se esbozan algunos de los puntos que a mediano y largo plazo se consideran que revisten gran importancia para el desarrollo del ordenamiento territorial local y regional;

- Se deben garantizar lineamientos generales en Ordenamiento Territorial que permitan generar modelos de ocupación locales que no riñan con los intereses regionales.

- Se deben definir responsabilidades institucionales para promover una política en Ordenamiento Territorial transversal tanto a los entes territoriales como a las entidades con competencia, que permita plantear modelos territoriales equilibrados.

- En el marco del desarrollo de una Ley Orgánica de Ordenamiento Territorial, procurar por incorporar los elementos básicos para promover cambios estructurales acordes con los requerimientos que Colombia necesita para afrontar las problemáticas territoriales.

- Se deben promover los procesos de saneamiento y delimitación de territorios étnicos.

- Generar espacios para el desarrollo de estrategias de acceso a tierras para habitantes en áreas de fuerte colonización, incluyendo posibilidades de redelimitación y sustracción de áreas muy intervenidas en Zonas de Reserva Forestal.

\section{Bibliografía.}

Corporación Ambiental de la Frontera Nororiental - CORPONOR, Plan de Gestión Ambiental Regional, San José de Cúcuta, 2002.

Corporación Ambiental de la Frontera Nororiental CORPONOR, Sistema de Información Ambiental Territorial - SIAT, San José de Cúcuta, 2003.

Instituto de Hidrología, Meteorología y Estudios Ambientales - IDEAM, Subdirección de Ecosistemas e Información Ambiental; Reservas Forestales ley $2^{\mathrm{a}}$ de 1959, Diagnóstico Estado Actual, Bogotá, 2003.

Ministerio del Medio Ambiente - Dirección General de Ecosistemas, Grupo Bosques; Reservas forestales del orden nacional, Bogotá, 2004.

\section{Legislación Colombiana Consultada}

Presidencia de la República de Colombia. Decreto 2811 de 1974, Por el cual se dicta el Código Nacional de Recursos Naturales Renovables y de Protección al Medio Ambiente.

República de Colombia, Congreso de la República. Constitución Política de Colombia de 1991.

República de Colombia, Congreso de la República. Ley 2 de 1959, por la cual se dictan normas sobre economía forestal de la Nación y conservación de recursos naturales renovables. 
República de Colombia, Congreso de la República. Ley 489 de 1998, por la cual se dictan normas sobre la organización y funcionamiento de las entidades del orden nacional.

Documentos técnicos consultados

Municipio de Convención, Esquema de Ordenamiento Territorial, Documento Técnico de Soporte, Convención, 2000.

Municipio de El Carmen, Esquema de Ordenamiento Territorial, Documento Técnico de Soporte, El Carmen, 2003.

Municipio de El Tarra, Esquema de Ordenamiento Territorial, Documento Técnico de Soporte, El Tarra, 2001.

Municipio de San Calixto, Esquema de Ordenamiento Territorial, Documento Técnico de Soporte, San Calixto, 2003.

Municipio de Teorama, Esquema de Ordenamiento Territorial, Documento Técnico de Soporte, Teorama, 2003.

Municipio de Tibú, Plan Básico de Ordenamiento Territorial, Documento Técnico de Soporte, Tibú, 2000.

Recursos de internet consultados

Parques Nacionales Naturales de Colombia. ¿Qué es el Sistema Nacional de Áreas Protegidas? Recuperado Mayo 8 de 2007 de http://www.parquesnacionales.gov.co/pnn/portel/libreria/php/decide.php?patron=01.11 